\title{
Promoting Moderate-Vigorous Physical Activity in Overweight Minority Girls
}

\author{
Norma Olvera, ${ }^{1}$ Marilynn Graham, ${ }^{1}$ Jessica McLeod, ${ }^{1}$ Stephanie F. Kellam, ${ }^{1}$ \\ and Nancy F. Butte ${ }^{2}$ \\ ${ }^{1}$ Department of Health and Human Performance, University of Houston, 3855 Holman Street, Room 104 Garrison Building, \\ Houston, TX 77204-6015, USA \\ ${ }^{2}$ Children's Nutrition Research Center, Baylor College of Medicine, USDA, 1100 Bates Avenue, Houston, TX 77030, USA
}

Correspondence should be addressed to Norma Olvera, nolvera@uh.edu

Received 28 December 2009; Revised 27 May 2010; Accepted 23 June 2010

Academic Editor: Neil Armstrong

Copyright (C) 2010 Norma Olvera et al. This is an open access article distributed under the Creative Commons Attribution License, which permits unrestricted use, distribution, and reproduction in any medium, provided the original work is properly cited.

\begin{abstract}
There is limited research on the types of activities that are most effective for promoting MVPA in children. Purpose. To assess which types of activities elicit MVPA in overweight minority girls. Methods. Sample consisted of 31 overweight (BMI $\geq 85$ th percentile) Latina and African-American girls (mean age 10.3 1.2 years). Participants wore an Actical accelerometer each day for 8 hours for 15 days to assess engagement in MVPA during their participation in a three-week activity intervention that included traditional fitness, sport skills, games, dancing, and flexibility sessions. Results. On average $62 \%$ of participants met the MVPA recommended guidelines $(60 \mathrm{~min} / 5 \mathrm{~d} / \mathrm{wk})$ with an average of $68.5 \pm 14$ minutes of MVPA across the three weeks. Traditional fitness sessions elicited the highest percent of MVPA (mean time spent in MVPA $=32 \%$ ), followed by dancing and games (mean time spent in MVPA $=21 \%$ ), sports skills (mean time spent in MVPA $=18 \%$ ), and flexibility (mean time spent in MVPA = 7\%). Step aerobics and rumba fitness elicited the highest proportions of MVPA. Conclusion. Traditional fitness activities were identified as the most successful in eliciting MVPA in overweight Latina and African American girls.
\end{abstract}

\section{Introduction}

Childhood overweight is a major health problem in the United States. The overweight prevalence defined as $>85$ th age- and gender-specific percentile for body mass index (BMI) in children and adolescents aged 2 to 19 years tripled between 1980 and 2002 [1-3]. A more recent estimate from the 2003-2004 National Health and Nutrition Examination Survey suggests that one out of three children in the United States is overweight [4]. The highest rates of overweight prevalence were reported for Mexican American children and African American girls.

Physical inactivity is deemed a major factor contributing to the energy imbalance that leads to excess adiposity [1]. The US Centers for Disease Control and Prevention (CDC) recommend that children and adolescents engage in 60 minutes of daily moderate to vigorous physical activity (MVPA) five out of seven days to achieve health benefits [5]. MVPA levels vary as a function of gender and age. Evidence indicates that only $42 \%$ of boys and $11 \%$ of girls meet $60 \mathrm{~min} \cdot \mathrm{d}^{-1}$ of MVPA [6]. Similar results have been reported in other studies [7-9]. Pate et al. [10] estimated the percentages of 1379 children and adolescents (aged 7 to 12 years) that met recommended physical activity guidelines using accelerometry. Results of this study revealed that in elementary school aged children exhibited $\geq 1$ hour of physical activity of at least moderate intensity on five or more days of the week. However, just $34 \%$ and $25 \%$ of adolescent boys and girls, respectively, met this guideline. Troiano et al. [11], using a national sample, reported that $49 \%$ of boys and $35 \%$ of girls between the ages 6-11 years engaged in the recommended amount of MVPA. However, by adolescence (aged 12-15 years), a significant decline occurred with only $12 \%$ of boys and $3.5 \%$ of girls achieving this goal. Similarly, data from the National Health and Nutrition Examination Survey 2003-2004 indicated that $52 \%$ of boys and $36 \%$ of girls between the ages $6-11$ years engaged in the recommended amount of MVPA. In contrast, only $15 \%$ and $3 \%$ of boys and girls, respectively, engaged 
in MVPA by ages between 12 and 15 years [12]. Overall, these studies indicate that girls are less likely to achieve the MVPA recommendation than boys and with age there is a severe decrease in the percentage of girls achieving the MVPA recommendation.

After controlling for age and gender, overweight children are likely to have lower levels of physical activity than their nonoverweight counterparts [13, 14]. In a study using a national sample, Whitt-Glover et al. [12] found that approximately $60 \%$ of normal weight children (aged 6-11 years) achieved MVPA recommendations compared to $31 \%$ of overweight children. Similarly, Deforche et al. [15] observed that compared to normal weight, overweight children had lower levels of physical activity. In a study of adolescents, having normal weight-for-age status was significantly associated with higher bouts of moderate to vigorous physical activity [16]. Trost et al. [17] compared physical activity patterns of 133 nonobese and 54 obese sixth-grade children. They observed that over a seven-day period obese children exhibited significantly lower daily accumulations of MVPA relative to their non-obese counterparts.

Ethnic differences in physical activity levels have also been observed, with Latino and African American children showing lower levels of physical activity than their White counterparts [18-22]. Moreover, among overweight Mexican-American and African-American children only approximately 30\% met MVPA guidelines. In a large study of Latino children, Butte et al. [23] observed that overweight adolescent girls had the lowest rates of MVPA. Inactivity in minority children, particularly, among overweight Latina girls, highlights the need to identify which types of physical activities might be effective in promoting the recommended amount of minutes of MVPA among overweight minority girls. Thus, the primary purpose of this exploratory study was to determine which types of physical activity generated greater amounts of MVPA in overweight minority girls. We assessed the contribution of 21 different physical activities (including traditional and nontraditional activities offered in school as well as culturally relevant activities) in eliciting 60 minutes of daily MVPA. These physical activities were grouped into five categories: traditional fitness, dance, games, sports skills, and flexibility. According to the CDC, to achieve MVPA guidelines children and adolescents should engage in aerobic or traditional fitness activities, games, sports skills, and dancing [24]. Based on a compendium of energy expenditure for youth [25], we hypothesized that traditional fitness activities would elicit the highest proportion of minutes of MVPA compared to flexibility sessions, with dance, games, and sport skills falling in the middle. We also tested several types of culturally relevant dances (e.g., rumba fitness, Salsa, and hip hop) since dancing has been identified as effective to increase physical activity in African-American girls [26].

\section{Methods}

2.1. Participants. Thirty-seven girls (27 Latina and 10 African American) participated in this study. They were part of a larger three-week family-based healthy lifestyle summer intervention titled Behavior Opportunities Uniting Nutrition, Counseling, and Exercise (BOUNCE) [27]. Girls' mean age was 10.8 years $(\mathrm{SD}=1.2$ years, range from 8 to 14 years). Study inclusion criteria included (1) selfidentification of Latino or African-American origin from parents and child; (2) age of child between 8 and 14 years; (3) child classified as overweight (body mass index (BMI) $\geq 85$ th to 94 th percentile for age) or obese (BMI $\geq 95$ th percentile for age); (4) a medical examination acknowledging that the child had no physical impediments that could hinder her participation in this study; (5) child's commitment to attend the entire study. Participants were recruited through flyers and referrals by school counselors, nurses, and teachers. Written informed assent and consent from the child and parents were obtained. The University of Houston Committee for the Protection of Human Subjects granted permission for the study to be conducted and approved all research protocols and consent/assent forms.

2.2. Intervention. As part of the BOUNCE intervention, girls participated in group sessions of exercise, nutrition education, and behavioral counseling for three weeks, 5 days (Monday-Friday) per week, from 9:00 AM to 5:00 PM each day. A detailed description of the nutrition and behavioral counseling components of the BOUNCE intervention are specified elsewhere [26]. For this section, we will focus on the description of the BOUNCE exercise program. As shown in Table 1, the BOUNCE exercise program was composed of 21 diverse group physical activities of varied target intensities (light 2 METs, moderate 3-5 METs, and vigorous 6 METs and above) according to the Ridley et al. [25] compendium. According to their types, physical activities were grouped into flexibility, sports skills, games, traditional fitness, and dance categories. We exposed participants to traditionally (e.g., sport skills) and nontraditionally offered physical activities (e.g., yoga, Pilates, ballet, cheerleading, rumba fitness, Salsa, modern and line dance) in school with the aim to engage participants in diverse, novel, and fun ways to be active.

The BOUNCE exercise program was standardized with a typical day beginning with a flexibility session (30 minutes) followed by a sports skills session (60 or 105 minutes) or games session (75 minutes). Lunch and a nutrition lesson were then followed by a traditional fitness session (60 minutes). Following a counseling session, the day would end with a dance session (60 minutes). Thus, participants engaged in four different physical activities daily. Each BOUNCE exercise session included 5-minute warm-up, light to vigorous physical activity, and 5-minute cool-down phases with an emphasis on continuous movement and minimal standing around in an effort to maintain a safe elevated heart rate. For example, participants were encouraged to move or march in place while listening to instructions or waiting their turn. Also, participants were encouraged to engage in the BOUNCE specific physical activities to the best of their abilities. We recognized that despite our best efforts some BOUNCE sessions (e.g., badminton) generated stationary periods among girls. 
TABLE 1: Weekly offered bounce exercise sessions.

\begin{tabular}{|c|c|c|c|c|c|c|}
\hline \multirow{2}{*}{ Category } & \multirow{2}{*}{ Activity } & \multirow{2}{*}{ Target intensity } & \multicolumn{4}{|c|}{${ }^{*}$ Duration (minutes) } \\
\hline & & & Week 1 & Week 2 & Week 3 & Total \\
\hline \multirow{3}{*}{ Flexibility } & Yoga/Stretching & \multirow{3}{*}{ Light } & 30 & 30 & 60 & 120 \\
\hline & Pilates/Stretching & & 30 & 30 & 30 & 90 \\
\hline & Ballet/Stretching & & 30 & 30 & 30 & 90 \\
\hline \multirow{6}{*}{ Sports skills } & Basketball & \multirow{6}{*}{ Light-moderate } & 60 & 0 & 60 & 120 \\
\hline & Walking & & 60 & 0 & 0 & 60 \\
\hline & Soccer & & 60 & 60 & 60 & 180 \\
\hline & Badminton & & 0 & 60 & 60 & 120 \\
\hline & Tennis & & 0 & 105 & 0 & 105 \\
\hline & Self defense & & 60 & 60 & 60 & 180 \\
\hline \multirow{2}{*}{ Games } & Survivor game & \multirow{2}{*}{ Light-moderate } & 75 & 0 & 0 & 75 \\
\hline & Amazing race & & 0 & 75 & 0 & 75 \\
\hline \multirow{4}{*}{ Traditional fitness } & Step aerobics & \multirow{4}{*}{ Moderate-vigorous } & 60 & 60 & 60 & 180 \\
\hline & Spinning/circuit & & 60 & 60 & 60 & 180 \\
\hline & Circuit training & & 0 & 60 & 60 & 120 \\
\hline & Kickboxing & & 60 & 60 & 0 & 120 \\
\hline \multirow{6}{*}{ Dancing } & Rumba fitness & \multirow{6}{*}{ Light-moderate } & 60 & 0 & 0 & 60 \\
\hline & Salsa & & 0 & 0 & 60 & 60 \\
\hline & Hip hop & & 60 & 60 & 60 & 180 \\
\hline & Cheerleading & & 60 & 60 & 60 & 180 \\
\hline & Modern dance & & 0 & 0 & 60 & 60 \\
\hline & Line dancing & & 0 & 60 & 0 & 60 \\
\hline
\end{tabular}

* Including 5 minutes warm-up and 5 minutes cool-down and instructional times.

Instructors certified by the nationally recognized Cooper Institute led exercise sessions at a gymnasium and dance studio located on a university campus. In addition, 3 exercise science undergraduate students assisted instructors and participants during the exercise sessions. For instance, during the exercise session these students mingled with the participants to encourage them with positive praise, to show them how to perform a movement, and to assist them if they were confused or not feeling well. Instructors and exercise assistants participated in four meetings prior to the BOUNCE program to discuss the standardization of the exercise program.

The BOUNCE exercise program was designed to be enjoyable and appealing by allowing participants to use various pieces of exercise equipment (e.g., colorful jump ropes, resistance bands, and hula hoops) and colead some of the exercise sessions, by using several of the participants' favorite music in the exercise sessions, and by partnering participants with others as "buddies." In addition, we employed other strategies to encourage active participation. First, we asked participants to sign a contract at the beginning of the exercise program by which they agreed to participate in all physical activities. Second, participants received weekly reports of their levels of physical activity achieved in the previous week. Third, prizes were awarded to participants who reached weekly goals. Fourth, participants received handouts on the exercise benefits, components of a healthy lifestyle, and strategies for overcoming barriers to being physically active.
2.3. Measures. Baseline demographic data consisted of questions about age, date and place of birth, and self-described ethnicity. Anthropometric assessments were conducted at baseline and postintervention and included body weight and height measured to the nearest $0.1 \mathrm{~kg}$ and $0.1 \mathrm{~cm}$, respectively, using a scale (Tanita TBF 215) and a stadiometer. Height was determined without shoes with the heels of both feet together and the toes pointed slightly outward at approximately a 60-degree angle, arms were at sides, and shoulders were level. Heels, buttocks, and back of the head were touching the vertical backboard and we lowered the headpiece until it firmly touched the crown of the head. BMI was calculated using Quetelet's index (body weight (kilograms)/height ${ }^{2}$ (meters)). BMI values were then used to identify the age- and gender-specific percentile for each child using CDC growth charts [28]. Based on these percentiles, each child was classified as overweight (85th-94th percentile for age and gender), or obese ( $\geq 95$ th percentile for age and gender) [28].

Actical accelerometers (Mini Mitter, a Respironics Co., Bend, OR) were used to measure frequency, duration, and intensity of physical activity objectively for 15 days. The Acti$\mathrm{cal}$ is a lightweight accelerometer built from a cantilevered rectangular piezoelectric bimorph plate and seismic mass, which is sensitive to movement in all directions. Actical stores movement information as activity counts. For the proposed study, each participant was shown the placement procedures for the Actical accelerometer at the right hip just 
above the iliac crest using an elastic strap and plastic buckle to secure the accelerometer around the waist. Participants were instructed to wear the accelerometer daily throughout the BOUNCE intervention (Monday-Friday) from arrival time to the end of the last BOUNCE exercise session. The Actical accelerometer was programmed to collect data from the beginning of the first exercise session at 9:00 AM until the end of the last exercise session at 5:00 PM. The accelerometers were set to record in 60-second epochs. Each day a research assistant logged the start and end times of each physical activity session and recorded the participant's attendance.

Upon completion of each five-day intervention week, accelerometer data (activity counts per minute) were downloaded into the Actical program and exported to an Excel spreadsheet for initial analysis. In the initial examination, data completeness was verified against an exercise log and attendance roster. After this initial data screening, activity counts were summed for each day and each activity. Activity counts per minute were partitioned as moderatevigorous (MVPA: $\geq 1500$ counts $\cdot \mathrm{min}^{-1}$ ), light (LPA: $>100$ $\left.<1500 \mathrm{c} \cdot \mathrm{m}^{-1}\right)$, and sedentary activity $\left(\mathrm{SA}: \leq 100 \mathrm{c} \cdot \mathrm{m}^{-1}\right.$ ) intensities using cutoff points developed by Puyau et al. [29]. The number of daily minutes spent at each intensity level was calculated by averaging the number of minutes spent at each intensity level (e.g., SA, LPA, and MVPA) across all participants for each day. The proportion of total activity time spent in MVPA (number of minutes at or above 1500 counts per minute divided by total time in each activity) was calculated for each of the 21 physical activity sessions. The MVPA achieved during these physical activity sessions was grouped into one of five general activity categories: flexibility, sports skills, games, traditional fitness, and dancing.

2.4. Statistical Analysis. Descriptive statistics (e.g., means, standard deviations, ranges) were calculated for all variables. The primary study variables included the average number of daily minutes spent in MVPA as well as LPA and SA. Repeated measures ANOVA with repeated contrasts was employed to determine changes in the average daily minutes of MVPA with each successive week of the program (i.e., week 1 to week 2 and week 2 to week 3 ) and to determine if the percent time spent in MVPA differed significantly among the activity categories. Alpha was set at 0.05. All statistical analyses were conducted using SPSS statistical package, version 15.0.

\section{Results}

3.1. Sample Characteristics. Of the 37 participants, data from six participants were excluded from the analysis because they did not have at least 12 days of accelerometer data reducing the final sample to 31 . No significant differences were found between those who completed at least 12 days of accelerometer data and those who did not. Twenty-three percent of the participants were classified as overweight and $77 \%$ were classified as obese with a mean $( \pm$ SD) BMI of 29.2 \pm 6.6 . The mean number of days that accelerometers were worn by each participant was $13.8 \pm 1.1$ days. Over half of the girls (59\%) came from low-income families as evidenced by receiving federally funded free school meal assistance.

3.2. Time (Minutes) Spent in MVPA. Girls' average time spent in MVPA improved each week (week $1=60.47$ minutes \pm 16.70 minutes, week $2=70.32$ minutes \pm 19.51 minutes, week $3=74.70$ minutes \pm 15.67 minutes). These improvements were statistically significant $(P<.01)$ both from week 1 to week 2 , and from week 2 to week 3 with an average of $68.5 \pm 14$ minutes of MVPA across the three weeks of the study. Fifty-six percent of girls met MVPA guidelines during week 1, 66\% of girls during week 2 and $63 \%$ during week 3 with an average of $62 \%$ of the girls meeting MVPA guidelines from 9:00 AM-5:00 PM period when accelerometers were worn.

3.3. Proportion of Time Spent in MVPA during Specific Physical Activities. Participants' percentage of time spent in MVPA across each of the different 21 physical activity sessions is presented in Figure 1. The percentage of time spent in MVPA ranged from 6\% (Pilates) to 35\% (step aerobics and rumba fitness). The average percentage of time spent in MVPA across the five general activity categories (traditional fitness, dance, sports skills, games, and flexibility) is also presented. Overall, traditional fitness sessions elicited the highest percent MVPA (mean = $32 \pm 8 \%$ ), followed by dancing and games $($ mean $=21 \pm 9 \%)$, sports skills $($ mean $=$ $18 \pm 10 \%$ ), and flexibility (mean $=7 \pm 3 \%$ ).

A statistical analysis comparing MVPA across the five activity categories indicated that traditional fitness sessions yielded significantly more MVPA than dancing and games sessions $(P<.01)$. The amount of MVPA generated by dancing and games was not significantly different $(P=.66)$. However, dancing and games sessions elicited significantly more MVPA than sports skills sessions $(P=.03)$, and sports skills sessions elicited significantly more MPVA than flexibility sessions $(P<.01)$.

\section{Discussion}

The primary purpose of this exploratory study was to determine which types of physical activities generated the highest proportion of MVPA in overweight minority girls. Findings indicate that traditional fitness activities were the most effective in yielding the highest proportion of MVPA in overweight minority girls while flexibility activities were the least effective with sports skills, dance, and games falling in the middle. An examination of specific physical activities revealed that step aerobics and rumba fitness elicited the highest proportions of MVPA followed by spinning/circuit training and Salsa. In contrast, Pilates sessions elicited the least proportion of MVPA. Thus, these results suggest that it is advisable to offer a variety of traditional fitness activities as well as some culturally appropriate activities such as rumba fitness to elicit MVPA in overweight Latina and AfricanAmerican girls. 


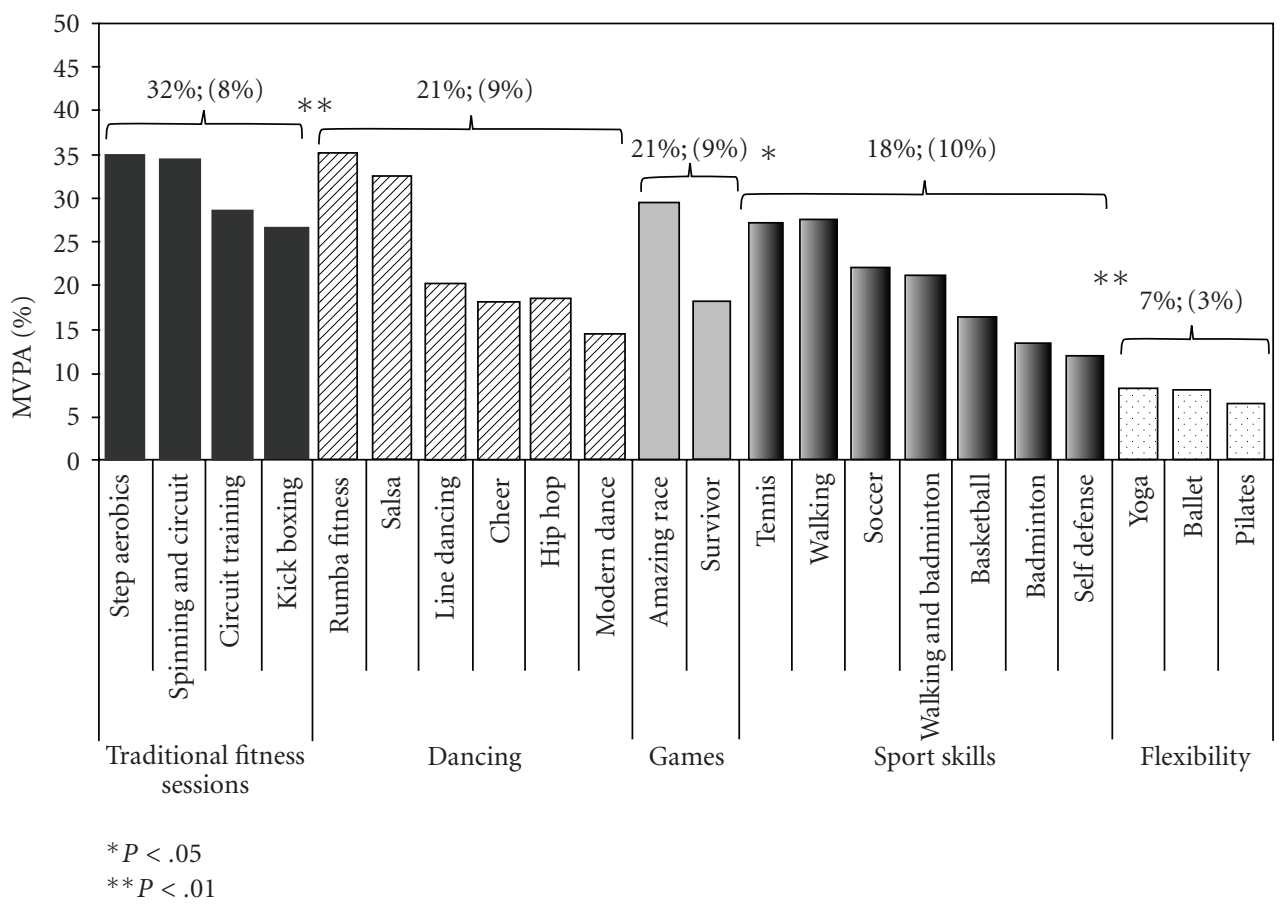

Figure 1: Mean and standard deviations of percentage of time spent in MVPA.

Based on objective measurements of physical activity, it was observed that on average, $62 \%$ of participants met MVPA recommended $60 \mathrm{~min} \cdot \mathrm{d}^{-1}$ guidelines and spent an average of $68.5 \pm 14$ minutes in MVPA during the 9:00 AM5:00 PM period when accelerometers were worn. Compared with the previous studies attempting to promote physical activity in minority girls [25, 30-32], our findings are quite noteworthy. In this study, the overweight girls participated in 210-225 minutes of daily physical activity (including approximately 40 minutes of warm-up and cool-down time). Given the fact that not all girls achieved the 60 minutes of MVPA, improvement is needed in motivating overweight girls to increase their PA intensity during the day. This fact not only highlights the need to develop interventions that include effective types of physical activities to achieve MVPA guidelines, but also to train instructors in motivational techniques.

To our knowledge, this is one of the few studies conducted with Latina and African-American girls which assessed MVPA objectively during 15 days of intermittent and sustained physical activity, matched with a valid record of physical activities offered during the intervention. The majority of research to date has focused on total daily minutes of physical activity in a free-living environment and has relied on self-report activity logs [33]. Some limitations of this exploratory study are noted including the small sample size and homogeneity of the sample (overweight and low-income minority girls) which limit the generalizability of the results to the general population of Latina and African-American girls of varied weight and socioeconomic status. Another limitation of this study is the lack of inclusion of psychosocial measures in order to assess participants' enjoyment, motivation, perceived competence, and/or self-efficacy for the activities involved. It would make a contribution to the literature to know if girls engage in more MVPA minutes in activities they claim to enjoy more. For instance, since we did not measure motivation, we could not address whether the highest proportion of MVPA generated by rumba fitness was due to the type of dance movements or due to the greater motivation of the girls or both. Despite the limitations this exploratory study provides valuable information regarding the most effective types of activities in eliciting MVPA in overweight Latina and African-American girls. Such information will guide researchers, physical education teachers, and health educators in designing more effective and culturally appropriate interventions intended to increase the daily amount of MVPA in high risk populations of overweight Latina and African-American girls.

\section{Acknowledgments}

The authors wish to thank the families who participated in this study. Our deepest appreciation is intended for all interns, volunteers, instructors, and coordinators, who spent countless hours in the preparation, implementation, and data collection of this study. In addition, we would like to recognize ARAMARK for contributing food and beverages to this study. This work was supported by St. Luke's Episcopal Health Charities Foundation, Oliver Foundation (0FG040307) and the University of Houston, College of Education Faculty Research Award Grant (0001449725).

\section{References}

[1] M. Dehghan, N. Akhtar-Danesh, and A. T. Merchant, "Childhood obesity, prevalence and prevention," Nutrition Journal, vol. 4, article 24, 2005. 
[2] A. A. Hedley, C. L. Ogden, C. L. Johnson, M. D. Carroll, L. R. Curtin, and K. M. Flegal, "Prevalence of overweight and obesity among US children, adolescents, and adults, 19992002," Journal of the American Medical Association, vol. 291, no. 23 , pp. 2847-2850, 2004.

[3] C. L. Ogden, K. M. Flegal, M. D. Carroll, and C. L. Johnson, "Prevalence and trends in overweight among US children and adolescents, 1999-2000," Journal of the American Medical Association, vol. 288, no. 14, pp. 1728-1732, 2002.

[4] C. L. Ogden, M. D. Carroll, L. R. Curtin, M. A. McDowell, C. J. Tabak, and K. M. Flegal, "Prevalence of overweight and obesity in the United States, 1999-2004," Journal of the American Medical Association, vol. 295, no. 13, pp. 1549-1555, 2006.

[5] Centers for Disease Control and Prevention, "Physical activity and health: a report to the surgeon general," June 2010, http://www.cdc.gov/physicalactivity/everyone/guidelines/index.html.

[6] B. S. Metcalf, L. D. Voss, J. Hosking, A. N. Jeffery, and T. J. Wilkin, "Physical activity at the government-recommended level and obesity-related health outcomes: a longitudinal study (Early Bird 37)," Archives of Disease in Childhood, vol. 93, no. 9, pp. 772-777, 2008.

[7] J. Mota, P. Santos, S. Guerra, J. C. Ribeiro, and J. A. Duarte, "Patterns of daily physical activity during school days in children and adolescents," American Journal of Human Biology, vol. 15, no. 4, pp. 547-553, 2003.

[8] S. D. Stovitz, L. M. Steffen, and A. Boostrom, "Participation in physical activity among normal- and overweight hispanic and non-hispanic white adolescents," Journal of School Health, vol. 78, no. 1, pp. 19-25, 2008.

[9] S. G. Trost, R. R. Rosenkranz, and D. Dzewaltowski, "Physical activity levels among children attending after-school programs," Medicine and Science in Sports and Exercise, vol. 40, no. 4, pp. 622-629, 2008.

[10] R. R. Pate, P. S. Freedson, J. F. Sallis et al., "Compliance with physical activity guidelines: prevalence in a population of children and youth," Annals of Epidemiology, vol. 12, no. 5, pp. 303-308, 2002.

[11] R. P. Troiano, D. Berrigan, K. W. Dodd, L. C. Mâsse, T. Tilert, and M. McDowell, "Physical activity in the United States measured by accelerometer," Medicine and Science in Sports and Exercise, vol. 40, no. 1, pp. 181-188, 2008.

[12] M. C. Whitt-Glover, W. C. Taylor, M. F. Floyd, M. M. Yore, A. K. Yancey, and C. E. Matthews, "Disparities in physical activity and sedentary behaviors among US children and adolescents: prevalence, correlates, and intervention implications," Journal of Public Health Policy, vol. 30, no. 1, pp. S309-S334, 2009.

[13] J. C. Eisenmann, R. T. Bartee, and M. Q. Wang, "Physical activity, TV viewing, and weight in U.S. youth: 1999 Youth Risk Behavior Survey," Obesity Research, vol. 10, no. 5, pp. 379-385, 2002.

[14] A. V. Rowlands, D. K. Ingledew, and R. G. Eston, "The effect of type of physical activity measure on the relationship between body fatness and habitual physical activity in children: a metaanalysis," Annals of Human Biology, vol. 27, no. 5, pp. 479-497, 2000 .

[15] B. Deforche, J. Lefevre, I. De Bourdeaudhuij, A. P. Hills, W. Duquet, and J. Bouckaert, "Physical fitness and physical activity in obese and nonobese Flemish youth," Obesity Research, vol. 11, no. 3, pp. 434-441, 2003.

[16] P. Gordon-Larsen, L. S. Adair, and B. M. Popkin, "Ethnic differences in physical activity and inactivity patterns and overweight status," Obesity Research, vol. 10, no. 3, pp. 141149, 2002.
[17] S. G. Trost, L. M. Kerr, D. S. Ward, and R. R. Pate, "Physical activity and determinants of physical activity in obese and non-obese children," International Journal of Obesity, vol. 25, no. 6, pp. 822-829, 2001.

[18] M. M. Fahlman, H. L. Hall, and R. Lock, "Ethnic and socioeconomic comparisons of fitness, activity levels, and barriers to exercise in high school females," Journal of School Health, vol. 76, no. 1, pp. 12-17, 2006.

[19] G. K. Singh, M. D. Kogan, P. C. Van Dyck, and M. Siahpush, "Racial/ethnic, socioeconomic, and behavioral determinants of childhood and adolescent obesity in the United States: analyzing independent and joint associations," Annals of Epidemiology, vol. 18, no. 9, pp. 682-695, 2008.

[20] P. Gordon-Larsen, R. G. McMurray, and B. M. Popkin, "Determinants of adolescent physical activity and inactivity patterns," Pediatrics, vol. 105, no. 6, p. E83, 2000.

[21] S. D. Stovitz, L. M. Steffen, and A. Boostrom, "Participation in physical activity among normal- and overweight hispanic and non-hispanic white adolescents," Journal of School Health, vol. 78, no. 1, pp. 19-25, 2008.

[22] E. M. F. Van Sluijs, A. M. McMinn, and S. J. Griffin, "Effectiveness of interventions to promote physical activity in children and adolescents: systematic review of controlled trials," British Medical Journal, vol. 335, no. 7622, pp. 703-707, 2007.

[23] N. F. Butte, M. R. Puyau, A. L. Adolph, F. A. Vohra, and I. Zakeri, "Physical activity in nonoverweight and overweight hispanic children and adolescents," Medicine and Science in Sports and Exercise, vol. 39, no. 8, pp. 1257-1266, 2007.

[24] Centers for Disease Control and Prevention, "Measuring Physical Activity Intensity," April 2010, http://www.cdc.gov/ physicalactivity/everyone/measuring/index.html.

[25] K. Ridley, B. E. Ainsworth, and T. S. Olds, "Development of a compendium of energy expenditures for youth," International Journal of Behavioral Nutrition and Physical Activity, vol. 5, article 45, 2008.

[26] T. N. Robinson, J. D. Killen, H. C. Kraemer et al., "Dance and reducing television viewing to prevent weight gain in AfricanAmerican girls: the Stanford GEMS pilot study," Ethnicity and Disease, vol. 13, no. 1, pp. S65-S77, 2003.

[27] N. Olvera, R. Scherer, J. McLeod et al., "BOUNCE: an exploratory healthy lifestyle summer intervention for girls," American Journal of Health Behavior, vol. 34, no. 2, pp. 144$155,2010$.

[28] Centers for Disease Control and Prevention, "Defining overweight and obesity," August 2008, http://www.cdc.gov/ healthyweight/assessing/bmi/index.html.

[29] M. R. Puyau, A. L. Adolph, F. A. Vohra, I. Zakeri, and N. F. Butte, "Prediction of activity energy expenditure using accelerometers in children," Medicine and Science in Sports and Exercise, vol. 36, no. 9, pp. 1625-1631, 2004.

[30] J. Stevens, D. M. Murray, D. J. Catellier et al., "Design of the trial of activity in adolescent girls (TAAG)," Contemporary Clinical Trials, vol. 26, no. 2, pp. 223-233, 2005.

[31] T. Baranowski, J. C. Baranowski, K. W. Cullen et al., "The Fun, Food, and Fitness Project (FFFP): the Baylor GEMS pilot study," Ethnicity and Disease, vol. 13, no. 1, supplement 1, pp. S30-S39, 2003.

[32] E. B. Kelly, D. Parra-Medina, K. A. Pfeiffer et al., "Correlates of physical activity in black, hispanic, and white middle school girls," Journal of Physical Activity and Health, vol. 7, no. 2, pp. 184-193, 2010. 
[33] J. Dollman, A. D. Okely, L. Hardy, A. Timperio, J. Salmon, and A. P. Hills, "A hitchhiker's guide to assessing young people's physical activity: deciding what method to use," Journal of Science and Medicine in Sport, vol. 12, no. 5, pp. 518-525, 2009. 


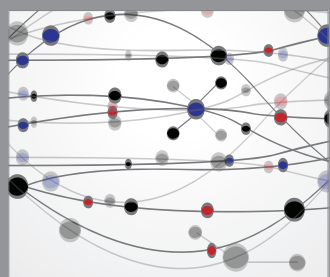

The Scientific World Journal
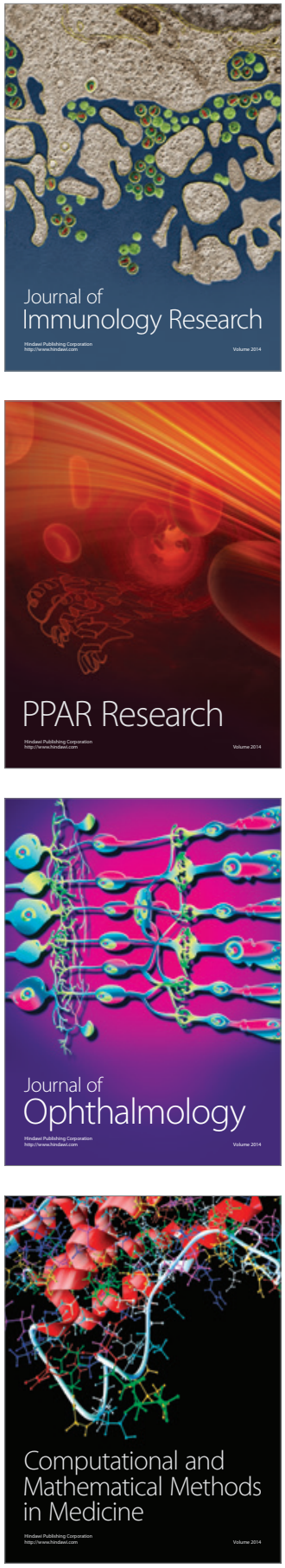

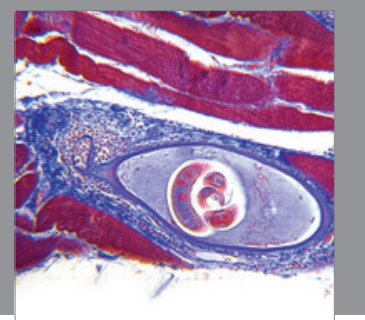

Gastroenterology

Research and Practice
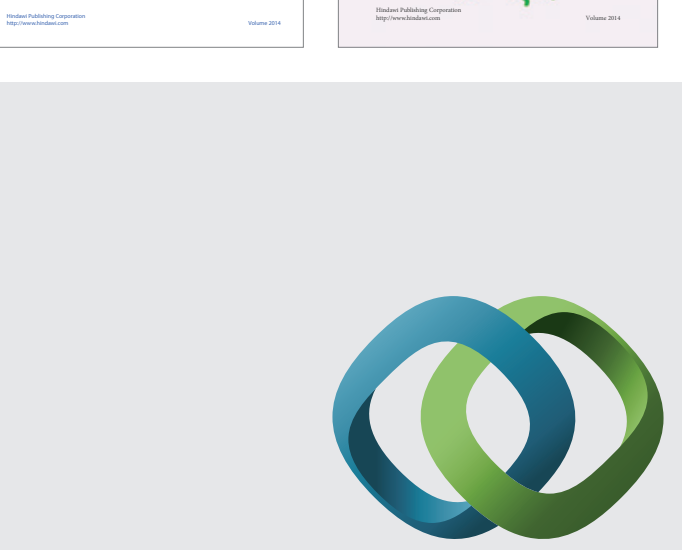

\section{Hindawi}

Submit your manuscripts at

http://www.hindawi.com
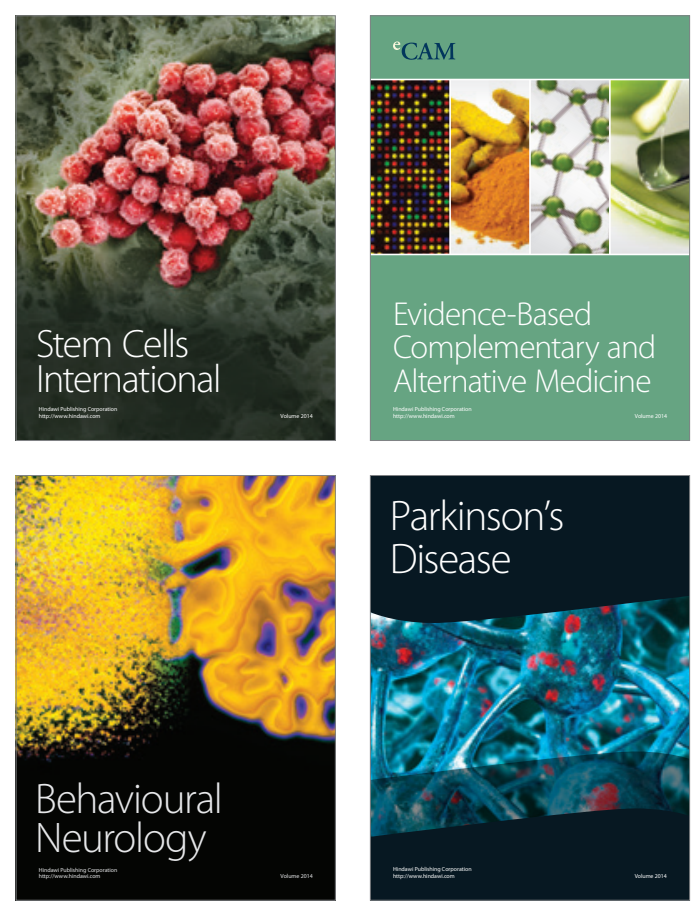

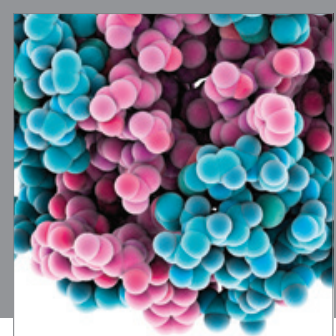

Journal of
Diabetes Research

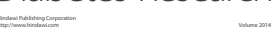

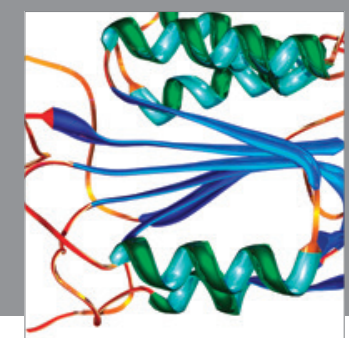

Disease Markers
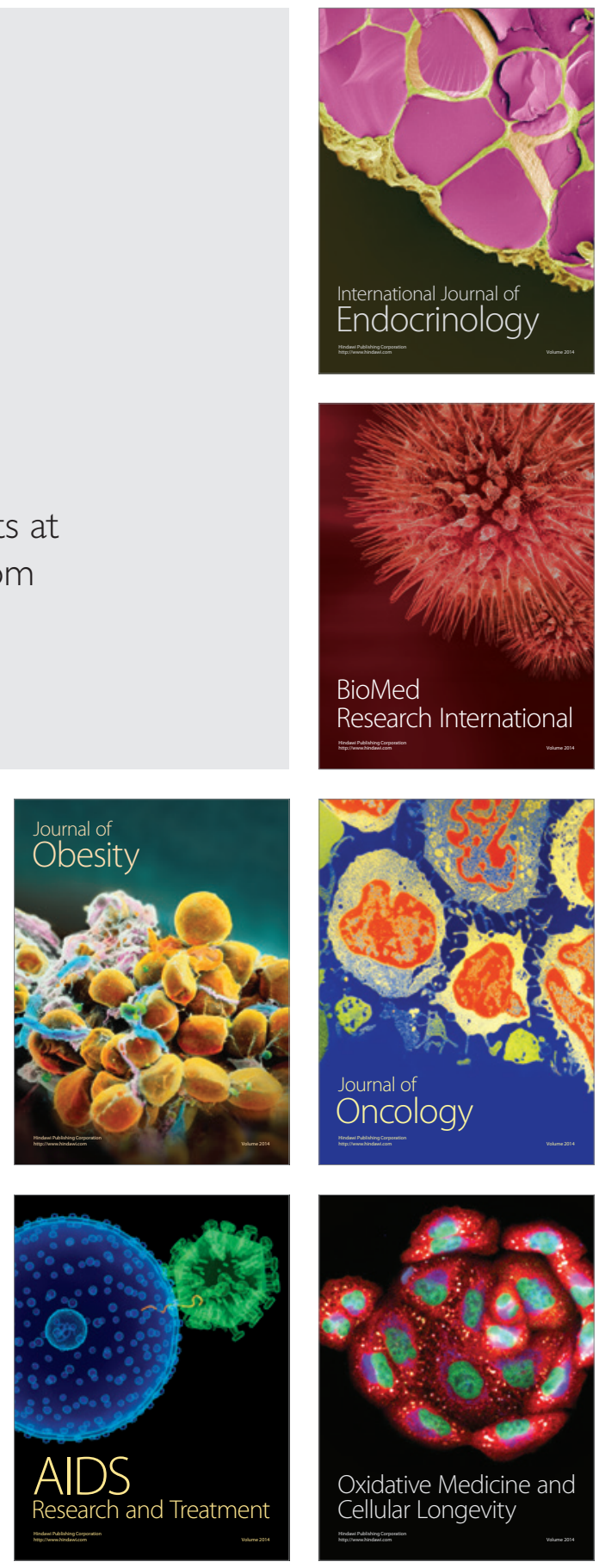